\title{
Seroprevalence and associated risk factors for Hepatitis B virus infection among barbers and their clients in two cities in Cameroon
}

Joël Brice Ngoupa, Patrick Achiangia Njukeng, Eric Ngoh Akwa, Michel Kengne, Ubald Tamoufe, Daniel Ter Goon \& Julius Nwobegahay

To cite this article: Joël Brice Ngoupa, Patrick Achiangia Njukeng, Eric Ngoh Akwa, Michel Kengne, Ubald Tamoufe, Daniel Ter Goon \& Julius Nwobegahay (2019): Seroprevalence and associated risk factors for Hepatitis $B$ virus infection among barbers and their clients in two cities in Cameroon, Southern African Journal of Infectious Diseases, DOI: 10.1080/23120053.2018.1558640

To link to this article: https://doi.org/10.1080/23120053.2018.1558640

(C) 2019 The Author(s). Co-published by NISC Pty (Ltd) and Informa UK Limited, trading as Taylor \& Francis Group

Published online: 07 Jan 2019.

Submit your article to this journal $\pi$

Llll Article views: 203

View Crossmark data $₫$ 


\title{
Seroprevalence and associated risk factors for Hepatitis B virus infection among barbers and their clients in two cities in Cameroon
}

\author{
Joël Brice Ngoupa ${ }^{a}$, Patrick Achiangia Njukeng ${ }^{b}$, Eric Ngoh Akwac, Michel Kengne ${ }^{a}$, Ubald Tamoufe ${ }^{d}$, Daniel Ter Goon ${ }^{e}$ and \\ Julius Nwobegahay ${ }^{\mathrm{a}, \mathrm{f*}}$
}

\author{
${ }^{a}$ Department of Microbiology/Immunology, Catholic University of Central Africa, Cameroon \\ ${ }^{b}$ Department of Microbiology and Parasitology, University of Buea, Cameroon \\ 'Department of Military Health Military Hospital, Douala, Cameroon \\ ${ }^{d}$ Metabiota Cameroon, Yaounde, Cameroon \\ ${ }^{e}$ Department of Nursing Science, University of Fort Hare, South Africa \\ ${ }^{f}$ Department of Military Health, Military Health Research Center (CRESAR), Yaounde, Cameroon \\ *Corresponding author, email: nwobegahay@yahoo.com
}

Background: Hepatitis B virus (HBV) infection is a serious public health problem in Africa and worldwide. Barbers are regularly in contact with the blood fluid of their clients, who could develop skin cuts and abrasions during shaving practices. There is scarcity of information about HBV among barbers in Cameroon. This study presents seroprevalence and associated risk factors for HBV infection among barbers and their clients in two cities (Yaounde and Douala) in Cameroon.

Methods: Three millilitres of venous blood was collected into EDTA tubes from each of the 262 consenting participants. Plasma was obtained and transported to the Military Health Research Centre (CRESAR) for analysis. Sociodemographic data were collected using a structured questionnaire. The prevalence of Hepatitis B surface antigen ( $\mathrm{HBs} A g)$ was determined by a rapid diagnostic test (DiaSpot HBsAg) and confirmed with an ELISA sandwich test. Data were analysed using SPSS, version 21.

Results: Thirty-three participants tested positive, giving an overall prevalence of $12.6 \%$. A seroprevalence of $15.0 \%$ and $10.6 \%$ was obtained for barbers and their clients respectively. In Yaounde, the frequency of HBsAg among barbers and their clients was $14.9 \%$ and $10.4 \%$ respectively, while in Douala it was $15.4 \%$ and $11.1 \%$ respectively. However, no statistically significant difference was observed in these groups. There was also no statistically significant association between the knowledge of the modes of HBV transmissions and HBV status.

Conclusion: The present study reveals that the rate of $\mathrm{HBsAg}$ among the study population is high in Cameroon and most people are not still properly sensitised regarding prevention measures.

Keywords: seroprevalence, Hepatitis B virus, barbers, risk factors

\section{Introduction}

Hepatitis causes serious mortality, morbidity and financial burden and is a serious global health problem. Worldwide, two billion people are infected by Hepatitis B virus (HBV) with about 400 million chronically infected cases. ${ }^{1}$ The prevalence of HBV varies from one place to another and can be divided into regions of high, medium and low endemicity. In low prevalence areas like the United States, Northern Europe, Australia and parts of South America, the incidence of HBV carrier rate is less than $2 \%$. HBV carrier rate is $2-8 \%$ in moderate prevalence areas such as the Middle East, some Eastern Europe countries and the Mediterranean basin. The carrier rate is above $8 \%$ in high endemic areas such as the Central Asian republics, Southeast Asia, sub-Saharan Africa and the Amazon basin. ${ }^{2}$ HBV can be transmitted through reuse of infected sharp objects, infected transfused blood, mother-to-child during birth, and through unsafe sex. ${ }^{3}$ The use of blades and razors is part of barbers' occupation and can expose them to customers' blood during hair shaving. ${ }^{4}$ In addition, HBV is $50-100$ times more infectious than HIV, and 10 times more infectious than Hepatitis $C$ virus $(\mathrm{HCV})$, hence has a lower infectious dose. Furthermore, it has been documented that HBV can survive outside the body for seven days or more on table tops, workbenches and other instruments, making it highly transmissible through contaminated razors and blades. ${ }^{5-7}$ In Cameroon, many researches have determined the seroprevalence of HBV in different study groups, but very limited data are available on the prevalence of HBV among barbers and their clients. The objective of our study was to determine the seroprevalence and knowledge of $\mathrm{HBsAg}$ among barbers and their clients.

\section{Methods}

This was a cross-sectional prospective study carried out from March to July 2017 in two cities in Cameroon. Information on barbers and clients was collected in the salon using a structured questionnaire containing sociodemographic characteristics, knowledge of HBV infection, observed shaving practices, characteristics of barbers' salons and potential risk factors of HBV infection. Three millilitres $(3 \mathrm{ml})$ of venous blood was collected from 262 participants into $5 \mathrm{ml}$ EDTA tubes. Plasma was obtained and transported to the Military Health Research Centre (CRESAR) for analysis. All these samples were tested using the Rapid Diagnostic Test (DiaSpot HBsAg One Step Hepatitis B Surface Antigen Test Strip; Sam-Tech Diagnostics, Nairobi, Kenya). All reactive samples were confirmed with an antibody sandwich ELISA technique (Golden Bio Technologies, California, USA). Ethical clearance was obtained from the Institutional Ethics Committee for Human Health Research of the Catholic University of Central Africa. Authorisations to collect samples were obtained from the Director of the School of Health Sciences and the Divisional Officers of the Mfoundi and Wouri Divisions of Cameroon. Informed consent was obtained from all the participants. Data 
were analysed using the Statistical Package for the Social Sciences (SPSS) version 21 (IBM Corp, Armonk, NY, USA). Demographic and other characteristics were compared using Pearson chi-square tests.

\section{Results}

Of the 319 participants approached, 282 consented and 262 completed the enrolment process, giving a percentage acceptance of $82.1 \%$. According to the distribution of the population by sex, $233(89 \%)$ were males, while $29(11 \%)$ were females with a male:female sex ratio of 8:1. The participants' ages varied from 2 to 62 years, with mean ages of 29.42 and 31.29 for barbers and clients, respectively; $61.1 \%$ were aged between 21 and 30 years; $60.7 \%$ had secondary level education, $81.3 \%$ were single and $72.5 \%$ had a salary less than 100,000 Frs CFA.

Three participants were foreigners, amongst whom one was positive (33.3\%). Of the 262 participants, 33 were positive for $\mathrm{HBsAg}$, giving an overall prevalence of $12.6 \%$. Table 1 shows the distribution of the positive participants in Yaounde and Douala. The seroprevalence of HBV was higher in barbers than in clients in both towns, but this difference is not statistically significant $(p>0.05)$.

Among barbers and clients combined, $17 \%$ had not heard of HBV, while $36.3 \%$ had more than one source of information about HBV. Those familiar with this infection reported that their main sources of information were from word of mouth $(41.2 \%)$, television $(41.2 \%)$, radio $(20.7 \%)$, healthcare workers (17.2\%) and less commonly printed media (9.2\%).

As shown in Figure 1, the majority of the participants did not know about barbers' shaving instruments, blood transfusion, sexual intercourse, tattooing and mother-to-child as modes of transmission of HBV. Some $19 \%$ of our study population did not perceive themselves to be at risk of HBV infections.

Among barbers, $45.8 \%$ (55) changed the hair clipper after each client. All the barbers used either undiluted alcohol or sodium hypochlorite solution to sterilise their working instruments. Most (77.1\%) of the barbers sterilised razors with alcohol solution. In this study, there was a significant association between the practice of using sodium hypochlorite solution as an antiseptic for skin cuts and HBV infection status $(p<0.05)$. Those who carried out this practice had twice the chance of being infected by HBV than those who did not $(\mathrm{OR}=2.079)$. There was no statistically significant association between the other shaving practices of barbers and HBV infection status. There was also no statistically significant association between the barbershop characteristics and HBV infection status ( $p>$ 0.05) (Table 2).

There was a significant association between having multiple sex partners and HBV infection ( $p=0.043$ ) (Table 3$)$.

Among barbers and their clients, the chance of contracting HBV was higher in individuals with the following characteristics: age between 2 and 20 years, secondary school as level of education, single status, symptoms of liver disease, and use of drugs and alcohol. None of these risk factors were associated with HBV infection status (Table 4).

\section{Discussion}

In this study, the majority of our study population were males $(89 \%)$, and females represented a smaller proportion (11\%). Stratifying the prevalence data into various age groups, the highest number of HBV-positive individuals was seen among participants in the age group 21-30 years. This could be the result of their risky lifestyles. ${ }^{8}$ In addition, Khan and colleagues ${ }^{9}$ established that younger and older people are less frequently infected with HBV. Adoba and colleagues ${ }^{4}$ showed in a cross-sectional study that the highest frequency of $\mathrm{HBsAg}$ infection was observed in barbers within the age range 20-29 years.

The prevalence of HBV infection varies from country to country and even from one region to another, depending on environmental factors and host characteristics. In many developing

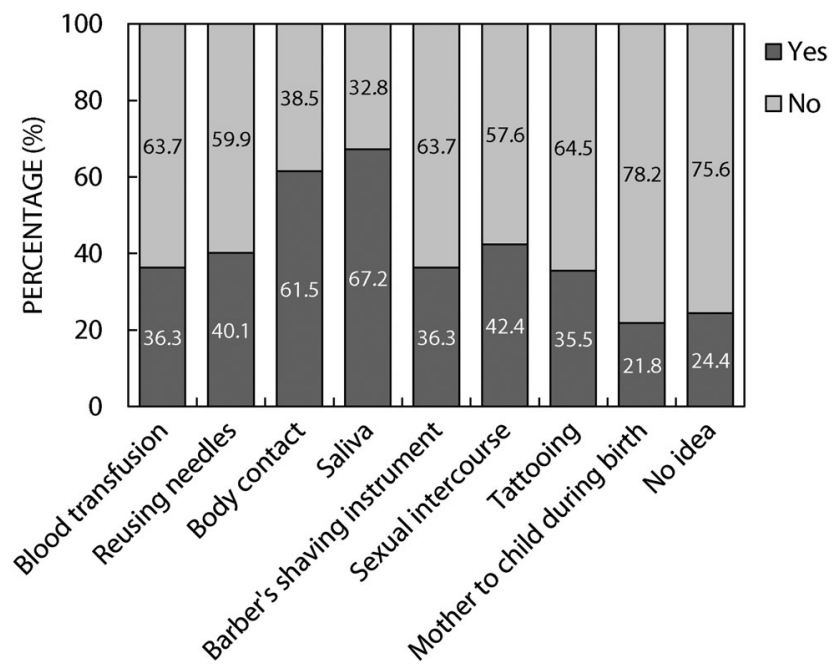

Figure 1: Knowledge of the modes of transmission of HBV.

Table 1: Distribution of the HBV-positive participants in Yaounde and Douala

\begin{tabular}{|c|c|c|c|c|c|}
\hline \multirow[b]{2}{*}{ Town } & & & Results & \multirow[b]{2}{*}{ Total } & \multirow[b]{2}{*}{ \% Seropositivity } \\
\hline & & & Positive & & \\
\hline \multirow[t]{3}{*}{ Yaounde } & & Barber & 14 & 94 & 14.9 \\
\hline & & Client & 11 & 106 & 10.4 \\
\hline & \multicolumn{2}{|l|}{ Total } & 25 & 200 & 12.5 \\
\hline \multirow[t]{3}{*}{ Douala } & & Barber & 4 & 26 & 15.4 \\
\hline & & Client & 4 & 36 & 11.1 \\
\hline & \multicolumn{2}{|l|}{ Total } & 8 & 62 & 12.9 \\
\hline \multirow[t]{3}{*}{ Total } & & Barber & 18 & 120 & 15.0 \\
\hline & & Client & 15 & 142 & 10.6 \\
\hline & \multicolumn{2}{|l|}{ Total } & 33 & 262 & 12.6 \\
\hline
\end{tabular}


Table 2: Observed shaving practices of barbers and characteristics of barbershops and the risk of HBV infection

\begin{tabular}{|c|c|c|c|c|c|}
\hline Factor & Total (\%) & Positive (\%) & Negative (\%) & OR $(95 \% \mathrm{Cl})$ & $p$-value \\
\hline \multicolumn{6}{|c|}{ Barber's shaving practices: } \\
\hline \multicolumn{6}{|c|}{ Uses sodium hypochlorite solution as antiseptic for skin cuts } \\
\hline Yes & $75(28.63)$ & $15(45.50)$ & $60(26.2)$ & \multirow[t]{2}{*}{$2.347(1.113-4.949)$} & \multirow[t]{2}{*}{0.022} \\
\hline No & $187(71.37)$ & $18(54.50)$ & $169(73.8)$ & & \\
\hline \multicolumn{6}{|c|}{ Barbershop characteristics: } \\
\hline \multicolumn{6}{|c|}{ Shop situated at an open-air market area } \\
\hline Yes & $20(7.63)$ & $0(0.00)$ & $20(8.70)$ & & \multirow[t]{2}{*}{0.077} \\
\hline No & $242(92.37)$ & $33(100)$ & $209(91.30)$ & & \\
\hline
\end{tabular}

Table 3: Number of sexual partners according to HBV status

\begin{tabular}{|l|c|c|c|}
\hline \multirow{2}{*}{ Number of sexual partners } & \multicolumn{2}{|c|}{ Results } \\
\cline { 1 - 3 } & Positive & Negative & Total \\
\hline 1 & 2 & 12 & 14 \\
\hline 2 & 10 & 99 & 109 \\
\hline 3 & 9 & 54 & 63 \\
\hline 4 & 5 & 36 & 41 \\
\hline 5 & 0 & 15 & 15 \\
\hline 6 & 5 & 6 & 11 \\
\hline 7 & 1 & 1 & 2 \\
\hline 8 & 0 & 1 & 1 \\
\hline 10 & 0 & 1 & 1 \\
\hline Total & 1 & 4 & 5 \\
\hline
\end{tabular}

countries, barbers earn a living by providing shaving services in marketplaces and on the street. ${ }^{10}$ The lack of strict hygiene conditions during the use of sharp instruments may be a risk factor for blood-borne infection causing health problems for both the barbers and their clients. ${ }^{11}$ In this study, HBsAg was found in $12.6 \%$ of the participants. Different rates have been reported in other occupational groups in Cameroon: $11.2 \%$ among blood donors, ${ }^{3} 7.1 \%$ among bank employees ${ }^{12}$ and $11.9 \%$ as obtained during the demographic survey carried out in $2011 .^{13}$ This higher prevalence might be due to the higher risk and constant exposure to blood fluid as compared with other study groups.

The frequency of $\mathrm{HBsAg}$ was higher among barbers (15.0\%) than among clients (10.6\%). Comparing each region where the study was conducted, the prevalence of HBV was again higher among barbers than among clients. This high prevalence is probably due to the fact some of the barbers do not use gloves for shaving, and might not wash or disinfect their hands. It is also likely that most of these barbers were not trained to carry out this activity for a living. These results corroborate with those in Morocco and Egypt showing an increased risk of HBV among barbers as opposed to their clients. ${ }^{14,15}$

Many of the participants had poor information concerning the routes of transmission of HBV. There was a statistically significant association between those who knew about direct body contact as a mode of transmission of HBV, those who had no idea about the modes of transmission of HBV and the level of education of the participants $(p=0.031$ and $p=0.004)$, respectively. This poor knowledge about the mode of transmission of HBV could be due to the lack of public sensitisation and free screening campaigns as in the case of HIV AIDS. It could also be due to the asymptomatic nature of the disease, which does not frequently raise attention. These results corroborate the study of Balbacha et al. ${ }^{14}$ who found that almost all traditional barbers and their clients did not know about the transmission of this bloodborne pathogen through shaving tools and other modes of infection. There was also a significant association between the act of having multiple sex partners and HBV infection. This could be due to the high level of exposure. Similar results were obtained by Inoue and Tanaka. ${ }^{16}$

The use of sodium hypochlorite solution as an antiseptic for skin cuts was significantly associated with HBV infection status and was also a risk factor for this disease. This result is normal because bleach is not supposed to be used as a topical antiseptic. In addition, this could be accounted for by the fact that barbers did not buy ready-prepared solutions of sodium hypochlorite and hence either used a highly concentrated solution, which will just fix the virus, or used over diluted solutions, which will have no effect on the virus, since most of them carried out this activity to earn a living and were not trained. There was no statistically significant association between barbers' shaving practices such as cleaning the razor with alcohol solution, changing hair clippers for each client, appropriate disinfection of skin cuts and HBV infection. There was also no statistically significant association between the risk factors such as symptoms of liver disease, history of past surgery, visiting traditional healers, use of drugs, use of alcohol, smoking and HBV infection. This could be attributed to the sample size and the sample technique used. Similar results were obtained by Balbacha and colleagues. ${ }^{14}$

Although HBV infection is generally known to be an asymptomatic disease, in our study a high number of HBV positive participants (30.3\%) had symptoms of the disease (right upper quadrant pains, nausea, prolonged headache, fatigue or even jaundice). This might be attributed to long-term infection by HBV. It might also be attributed to the type of nutrition and the genetic make-up of participants in the different geographical locations. The high level of symptomatic individuals among the participants in this study is different from the study of Tahereh and colleagues who showed that participants who were positive to $\mathrm{HBsAg}$ were asymptomatic. ${ }^{2}$

Even though it has been documented that HBV may survive outside the body for about one week or more on table tops, solid surfaces and instruments, in this study we could not determine whether the HBV infection was a result of the cross contamination during shaving practices. Another limitation to this study was the inability to use more sensitive diagnostic methods like Polymerase Chain Reaction (PCR), which would 
Table 4: Potential risk factors for HBV infection among barbers and their clients

\begin{tabular}{|c|c|c|c|c|c|}
\hline \multirow[b]{2}{*}{ Variable } & \multirow[b]{2}{*}{ Total (\%) } & \multicolumn{2}{|c|}{ HBV } & \multirow[b]{2}{*}{ OR $(95 \% \mathrm{Cl})$} & \multirow[b]{2}{*}{$p$-value } \\
\hline & & Positive (\%) & Negative (\%) & & \\
\hline \multicolumn{6}{|l|}{ Age (years): } \\
\hline $2-20$ & $14(5.34)$ & $3(9.1)$ & $11(4.8)$ & $1.982(0.523-7.512)$ & \multirow[t]{5}{*}{0.398} \\
\hline $21-30$ & $153(58.40)$ & $22(66.7)$ & $131(57.2)$ & $1.496(0.693-3.230)$ & \\
\hline $31-40$ & $65(24.81)$ & $7(21.2)$ & $58(25.3)$ & $0.794(0.327-1.926)$ & \\
\hline $41-50$ & $23(8.78)$ & $1(3.0)$ & $22(9.6)$ & $0.294(0.038-2.26)$ & \\
\hline $51-70$ & $7(2.67)$ & $0(0.0)$ & $7(3.1)$ & & \\
\hline \multicolumn{6}{|c|}{ Level of education: } \\
\hline University & $71(27.1)$ & $6(18.2)$ & $65(28.4)$ & $0.561(0.221-1.421)$ & \multirow[t]{4}{*}{0.484} \\
\hline Secondary & $159(60.7)$ & $23(69.7)$ & $136(59.4)$ & $1.573(0.715-3.458)$ & \\
\hline Primary & $27(10.3)$ & $4(12.1)$ & $23(10.0)$ & $1.235(0.399-3.827)$ & \\
\hline Not educated & $5(1.9)$ & $0(0.0)$ & $5(2.2)$ & & \\
\hline \multicolumn{6}{|l|}{ Marital status: } \\
\hline Single & $213(81.30)$ & 29 (87.9) & $184(80.34)$ & $1.773(0.593-5.300)$ & \multirow[t]{4}{*}{0.703} \\
\hline Married & 44 (16.79) & $4(12.1)$ & $40(17.47)$ & $0.652(0.217-1.957)$ & \\
\hline Divorces & $4(1.53)$ & $0(0.0)$ & $4(1.75)$ & & \\
\hline Widowed & $1(0.38)$ & $0(0.0)$ & $1(0.44)$ & & \\
\hline \multicolumn{6}{|l|}{ Alcohol use: } \\
\hline Yes & $197(75.19)$ & $29(87.88)$ & $168(73.36)$ & \multirow[t]{2}{*}{$2.632(0.889-7.796)$} & \multirow[t]{2}{*}{0.071} \\
\hline No & $65(24.81)$ & $4(12.12)$ & $61(26.64)$ & & \\
\hline \multicolumn{6}{|l|}{ Drug use: } \\
\hline Yes & $23(8.78)$ & $4(12.12)$ & $19(8.30)$ & \multirow[t]{2}{*}{$1.525(0.485-4.796)$} & \multirow[t]{2}{*}{0.468} \\
\hline No & $239(91.22)$ & $29(87.88)$ & $210(91.70)$ & & \\
\hline \multicolumn{6}{|c|}{ Symptoms of liver disease: } \\
\hline Yes & $59(22.52)$ & $10(30.30)$ & $49(21.40)$ & \multirow[t]{2}{*}{$1.597(0.713-3.579)$} & \multirow[t]{2}{*}{0.252} \\
\hline No & $203(77.48)$ & $23(69.70)$ & $180(78.60)$ & & \\
\hline
\end{tabular}

have help in detecting occult HBV infections. We did not also test for the different serological markers in order to differentiate between active and chronic HBV infection. This was due to lack of resources.

\section{Conclusions}

The seroprevalence of HBV infection is quite high in Yaounde and Douala. The seroprevalence of HBV among barbers is higher than among clients; hence barbers may be at higher risk of this blood burden as compared with their clients. Proper sterilisation of shaving instruments, safe-sex practices, immunisation and education of the general population should constitute an important package in a prevention programme. There was no association between the modes of transmissions of HBV and the HBV status, hence HBV status might be independent of the knowledge regarding modes of HBV transmission and highly dependent on the level of exposure to infection. Most people are still not properly sensitised regarding prevention measures. HBV infection might not only be attributable to shaving practices but might be due to other risk factors. The main focus should be on launching health education programmes, encouraging behaviour change and organising communication campaigns for barbers, clients and the general population in order to spread awareness.

Acknowledgements - The authors would like to thank all those who agreed to take part in this study, and also those who helped with sample testing.
Disclosure statement - No potential conflict of interest was reported by the authors.

\section{References}

1. Nkrumah B, Owusu M, Frempong HO, Averu P. Hepatitis B and C viral infections amongblood donors from rural Ghana. Ghana Med J. 2011;45(3):97-100.

2. Tahereh K, Ayat S, Azam R, Jalal K, Fatemeh V, Mina T, Saeed Z, Forough G, Fazel, S. Analysis of knowledge, attitudes, and prevalence of Hepatitis B and C seromarkersamong barbers in Tehran. Hepat. Mon. 2017;6(9):39416.

3. Nwobegahay JM, Njukeng PA, Kengne $M$, Ayangma CR, Abeng EM, Nkeza A, Tamoufe U. Prevalence of Hepatitis B virus infection among blood donors at the Yaounde Military Hospital, Cameroon. Net J. 2016;4(2):6-10.

4. Adoba P, Boadu SK, Agbodzakey H, Somuah D, Ephraim RK, Odame EA. High prevalence of hepatitis $B$ and poor knowledge on hepatitis $B$ and $C$ viral infections among barbers: a cross-sectional study of the Obuasi municipality, Ghana. BMC Public Health. 2015;15:1041. http:// doi.org/10.1186/s12889-015-2389-7.

5. Jokhio A, Bhatti T, Memon S. Knowledge, attitudes and practices of barbers about hepatitis $B$ and $C$ transmission in hyderabad, pakistan. East. Med. Health J. 2010;16:1079-84.

6. World Health Organization. Hepatitis B: World Health Organization, Fact sheet, 204.Geneva, Switzerland. 2017;http://www.who.int/ media centre/factsheets/fs204/en/

7. Pennap GR, Yakubu A, Oyige O, Forbi J. Prevalence of hepatitis B and $C$ virus infection among people of a local community in Keffi, Nigeria. Afr. J. Microbiol. Res. 2010;4(4):274-8.

8. Dongdem J, Kampo S, Soyiri I, Asebga P, Ziem J, Sagoe K. Prevalence of hepatitis B virus infection among blood donors at the tamale teaching hospital, Ghana (2009). BMC Res Notes. 2012;5:115. 
9. Khan F, Shams S, Qureshi DI, Israr M, Khan H, Sarwar TM, llyas M. Hepatitis $B$ virus infection among different sex and age group in Pakistani Punjab. Virology J. 2011;8:225. http://doi.org/10.1186/1743-422X-8-225.

10. Janjua NZ, Nizamy MA. Knowledge and practices of barbers about hepatitis $B$ and ctransmission in Rawalpindi and Islamabad. J Pak Med Assoc. 2004;54(3):116-9.

11. Mariano A, Mele A, Tosti ME, Parlato A, Gallo G, Ragni P. Role of beauty treatment in the spread of parenterally transmitted hepatitis viruses in Italy. J Med Virol. 2004;74(2):216-20.

12. Andoulo FA, Tagni-sartre M, Noah D, Djapa R, Ndam EC. Prevalence of Hepatitis B surface antigen in a population of workers in Cameroon. Open J. Gastroenterol. 2013;3:323-7.

13. Proceeding of National Agency for Research on AIDS and Viral Hepatitis. ANRS. Opening ceremony of the 6th scientific day. 2016.
14. Balbacha I, Cherkaoui I, Akrim M, Douley K, Aouad R. Seroprevalence of hepatitis $B$ and $C$ among barbers and their clients in the Rabat region of Morocco. East Med. Health J. 2010;17(12):911-9.

15. Shalaby S, Kabbash IA, Saleet G, Mansour N, Omar A, Nawawy A. Hepatitis $B$ and $C$ viral infection: prevalence, knowledge, attitude and practice among barbers and clients inGharbia governorate, Egypt. East Mediterr Health J 2010;16(1):10-7.

16. Inoue T, Tanaka Y. Hepatitis B virus and its sexually transmitted infection - an update. Microb Cell. 2016;3(9):420-437. http://doi.org/10. 15698/mic2016.09.527.

Received: 28-07-2018 Accepted: 10-12-2018 